\title{
Vision-based Crack Identification on the Concrete Slab Surface Using Fuzzy Reasoning Rules and Self-Organizing
}

\author{
Kwang Baek Kim ${ }^{1}$, Hyun Jun Park ${ }^{2}$, Doo Heon Song ${ }^{3}$ \\ ${ }^{1}$ Departement of Computer Engineering, Silla University, Republic of Korea \\ ${ }^{2}$ Department of Computer Engineering, Pusan National University, Republic of Korea \\ ${ }^{3}$ Department of Computer Games, Yong-In SongDam College, Republic of Korea
}

\section{Article Info \\ Article history: \\ Received Feb 4, 2016 \\ Revised Jun 29, 2016 \\ Accepted Jul 16, 2016 \\ Keyword: \\ Concrete slab structure \\ Crack identification \\ Fuzzy logic \\ Noise removal \\ Self organizing map}

\begin{abstract}
Identifying cracks on the surface of concrete slab structure is important for structure stability maintenance. In order to avoid subjective visual inspection, it is necessary to develop an automated identification and measuring system by vision based method. Although there have been some intelligent computerized inspection methods, they are sensitive to noise due to the brightness contrast and objects such as forms and joints of certain size often falsely classified as cracks. In this paper, we propose a new fuzzy logic based image processing method that extracts cracks from concrete slab structure including small cracks that were often neglected as noise. We extract candidate crack areas by applying fuzzy method with three color channel values of concrete slab structure. Then further refinement processes are performed with Self Organizing Map algorithm and density based noise removal process to obtain basic crack characteristic attributes for further analysis. Experimental result verifies that the proposed method is sufficiently identified cracks with various sizes with high accuracy (97.3\%) among 1319 ground truth cracks from 30 images.
\end{abstract}

Copyright (c) 2016 Institute of Advanced Engineering and Science. All rights reserved.

\section{Corresponding Author:}

Kwang Baek Kim,

Departement of Computer Engineering,

Silla University,

140 Baegyang-daero (Blvd) 700 beon-gil (Rd), Sasang-gu, Busan 46958, Republic of Korea.

Email: gbkim@silla.ac.kr

\section{INTRODUCTION}

Cracks in concrete slabs have harmful influence on the tolerance, durability, waterproofing, and appearance of the structure thus they should be measured correctly in time. There have been numerous studies using sensor technique [1] or from the structure health monitoring (SHM) point of view by vibrationbased methodologies for various structures in [2]-[6] and several reviews may summarize techniques and their characteristics in [7],[8].

While most SHM methods based on vibration analysis try to extract global modal features as signatures of structural integrity, Nondestructive Evaluation (NDE) methods, especially when two or higher dimensional imaging methods are employed, are able to provide a direct characterization of local structural damage [9]. Thus, we are interested in such an approach for identifying cracks in concrete slab structure with intelligent image processing.

In practice, engineers largely rely on visual inspection which is qualitative and subjective in nature that depends on the inspector's expertise [10]. Thus, it is much needed methodology to automate identifying and analyzing crack characteristics such as width, length and direction with image processing techniques [11].

Unfortunately, there is no firm mathematical model for the crack figures. And the concrete structure is exposed to the external environment right after the construction, consequently a perfect crack extraction 
method is yet to be developed. Various image processing techniques such as Wavelet transform, Fourier transform [12], advanced filtering [13], adaptive thresholding [14], percolation [15], C-V model [16], fractal dimension analysis [17], and incorporating statistical inference [18] for various goals.

One of the practical difficulties in developing automatic crack identification tool with image processing technique is removing noise effectively and accurately. Especially for concrete slab structure, it is much harder than that of vertical materials like walls in that frequently, forms and joints are falsely identified as cracks [19]. Even the tracks of water leaking could be misidentified as cracks since often times, the brightness contrast is not enough to discriminate such objects automatically.

Thus, previously we applied intelligent binarization procedures and image restoration treatment to reduce such false positives as shown in [11],[20],[21]. However, in practice, it is found that such methods have difficulties when there is no clear distinction in brightness between the crack and the surface and sensitive to the outdoor lights.

Thus, in this paper, we propose a method to overcome or at least mitigate such weaknesses. The highlights of our new method are extracting candidate crack areas with fuzzy reasoning which has been applied to many engineering areas successfully [22] by giving R, G, B channel values of concrete surface independently and removing noise from those candidates by Self Organizing Map (SOM) [23]. With such treatment, minute noises (less than $1 \mathrm{~cm}$ long) that were not removed before are successfully discriminated by the density distinction between the normal surface and the crack.

\section{IDENTIFYING CRACKS FROM CONCRETE SLAB SURFACE IMAGE}

The overall diagram of the proposed crack extraction method is as shown in Figure 1.

(a) Concrete Image
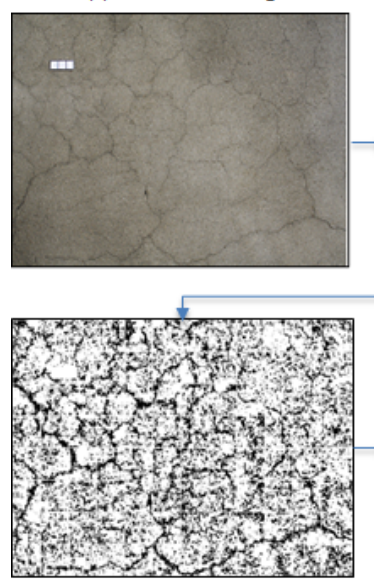

(e) Removing Base Line (b) Local Smoothing
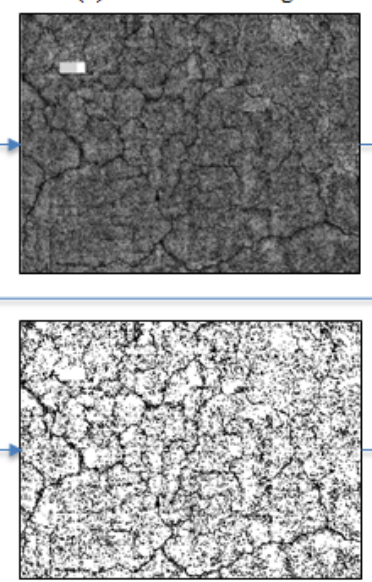

(f) Restoration of Crack Loss (c) Applying Fuzzy
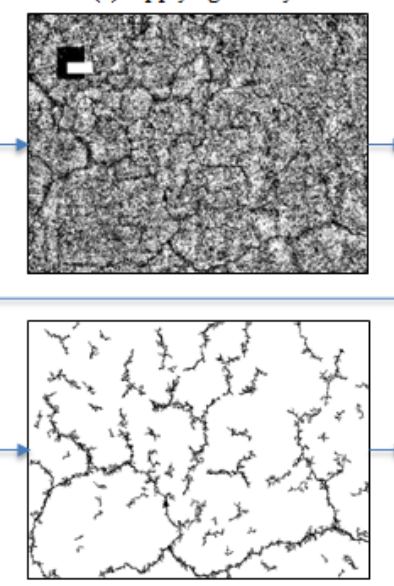

(g) Noise Removal by Density (d) Applying SOM
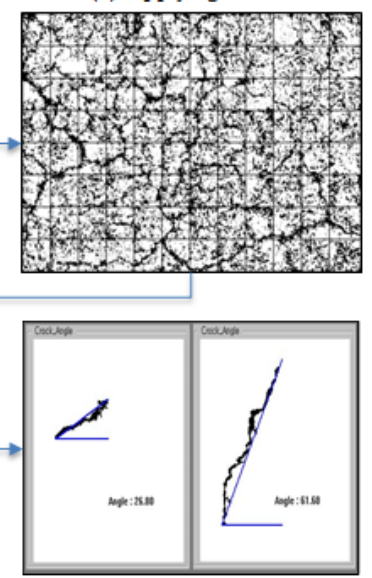

(h) Identifying Crack Characteristics

Figure 1. Algorithm outline

\subsection{Local Smoothing}

In order to enhance the brightness contrast, we use local smoothing technique which divides the image into multiple blocks and apply smoothing function Ski defined as formula (1) to each block.

$$
\begin{aligned}
& S_{k}^{i}=T^{i}\left(X_{k}\right) \sum_{j=0}^{k} P_{X}^{i}\left(X_{j}\right)=\sum_{j=0}^{k} \frac{n_{j}^{i}}{n^{i}} \\
& 0 \leq X_{k} \leq 1, \quad T^{i}\left(X_{L-1}\right)=\sum_{j=0}^{L-1} P_{X}^{i}\left(X_{j}\right)=1 \\
& f_{H E}^{i}=S_{k}^{i}(L-1)
\end{aligned}
$$

where $n^{i}$ denotes the number of pixels in the $i^{\text {th }}$ block and $n_{k}^{i}$ denotes the brightness value of $k^{\text {th }}$ brightest pixel in the $i^{\text {th }}$ block and $T_{i}\left(X_{k}\right)$ is the cumulated sum of histogram $P_{X}{ }^{i}\left(X_{j}\right)$ for each of $L$ blocks. The result of this process is to obtain enhanced normalized brightness value among $L$ blocks as defined in formula (1). 
Minute cracks are similar to noises in brightness. In order to distinguish them, we divide the original image to small objects and apply local smoothing method as following and the result is as shown in Figure 2 (b).

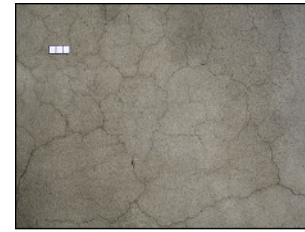

(a) Original image

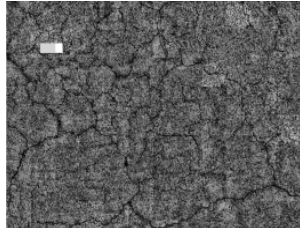

(b) After local moothing

Figure 2. Local smoothing effect

\subsection{Extracting Candidate Crack Areas with Fuzzy method}

The original concrete image may have low contrast such that the cracks and adjacent noise area have similar brightness range. Using this characteristic, we divide locally smoothed image into many small random objects and compute average gray value. Then for the area having below average gray value, we apply fuzzy method to R, G, B channel information with corresponding membership functions defined as Figure 3. Membership function range for Figure 1 is defined as Table 1 . The notation like $R(G, B)$ in Table 1 denotes the average color channel value in object area in $R, G, B$ channel in respectively. For example, in Table 3, variable V3 is determined as;

$$
\begin{aligned}
& \text { average }(\mathrm{R} \text { channel value }) \times(3 / 4) \text { in } \mathrm{R} \text { channel } \\
& \text { average }(\mathrm{G} \text { channel value }) \times(3 / 4) \text { in } \mathrm{G} \text { channel } \\
& \text { average }(\mathrm{B} \text { channel value }) \times(3 / 4) \text { in } \mathrm{B} \text { channel } \\
& \text { within }[0,255]
\end{aligned}
$$

and that variable notation $\mathrm{v} 3$ is on the $\mathrm{x}$-axis of Figure 3 (a)-(c) in respectively. By applying membership function as shown in Figure 3, we have fuzzy symbol R1-R4, G1-G4, B1-B4 with respect to the brightness value of the pixel.

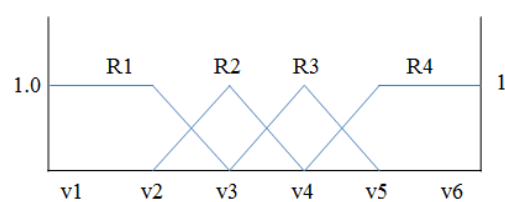

(a) R membership function

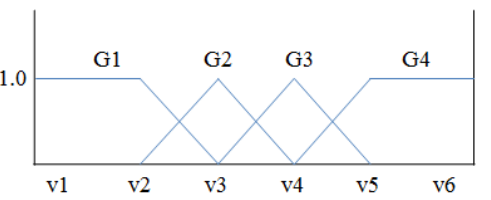

(b) G nembership function

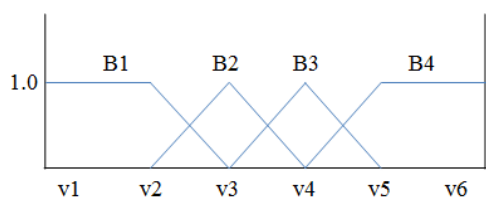

(c) B membership function

Figure 3. Membership functions of R, G, B Channel - first part

Table 1. Membership function range for Figure 3

\begin{tabular}{cc} 
v1 & 0 \\
v2 & $\mathrm{R}(\mathrm{G}, \mathrm{B}) / 2$ \\
v3 & $\mathrm{R}(\mathrm{G}, \mathrm{B}) *(3 / 4)$ \\
$\mathrm{v} 4$ & $\mathrm{R}(\mathrm{G}, \mathrm{B}) *(5 / 4)$ \\
v5 & $\mathrm{R}(\mathrm{G}, \mathrm{B}) *(6 / 4)$ \\
v6 & 255 \\
\multicolumn{2}{c}{$\mathrm{R}(\mathrm{G}, \mathrm{B})=$ average $\mathrm{R}(\mathrm{G}, \mathrm{B})$ in object area } \\
\hline
\end{tabular}


Then we can extract candidate crack areas by the following fuzzy reasoning rules. Again, this set of rules is symmetric with respect to the color channel $R, G$, and $B$ thus we denote range variable $R 1$, G1, and $\mathrm{B} 1$ with respect to the color channel as $\mathrm{R} 1(\mathrm{G} 1, \mathrm{~B} 1)$ for notational convenience.

\begin{tabular}{|c|c|}
\hline IF $\mathrm{X}$ is $\mathrm{R} 1(\mathrm{G} 1, \mathrm{~B} 1)$ and $\mathrm{Y}$ is $\mathrm{R} 1(\mathrm{G} 1, \mathrm{~B} 1)$ then $\mathrm{W}$ is $\mathrm{C} 1$ & IF $\mathrm{X}$ is $\mathrm{R} 3(\mathrm{G} 3, \mathrm{~B} 3)$ and $\mathrm{Y}$ is $\mathrm{R} 1(\mathrm{G} 1, \mathrm{~B} 1)$ then $\mathrm{W}$ is $\mathrm{C} 2$ \\
\hline IF $\mathrm{X}$ is $\mathrm{R} 1(\mathrm{G} 1, \mathrm{~B} 1)$ and $\mathrm{Y}$ is $\mathrm{R} 2(\mathrm{G} 2, \mathrm{~B} 2)$ then $\mathrm{W}$ is $\mathrm{C} 1$ & IF $\mathrm{X}$ is $\mathrm{R} 3(\mathrm{G} 3, \mathrm{~B} 3)$ and $\mathrm{Y}$ is $\mathrm{R} 2(\mathrm{G} 2, \mathrm{~B} 2)$ then $\mathrm{W}$ is $\mathrm{C} 3$ \\
\hline ת 10 & is $\mathrm{R} 3(\mathrm{G} 3, \mathrm{~B} 3)$ then $\mathrm{W}$ is $\mathrm{C} 3$ \\
\hline $\mathrm{d} \mathrm{Y}$ is $\mathrm{R} 4(\mathrm{G} 4, \mathrm{~B} 4) \mathrm{tl}$ & IF $\mathrm{X}$ is $\mathrm{R} 3(\mathrm{G} 3, \mathrm{~B} 3)$ and $\mathrm{Y}$ is $\mathrm{R} 4(\mathrm{G} 4, \mathrm{~B} 4)$ then $\mathrm{W}$ is $\mathrm{C} 4$ \\
\hline IF $X$ is $R 2(G 2, B 2)$ and $Y$ is $R 1(G 1, B 1)$ tl & $\mathrm{Y}$ is $\mathrm{R} 1(\mathrm{G} 1, \mathrm{~B} 1)$ then $\mathrm{W}$ is $\mathrm{C} 2$ \\
\hline IF $\mathrm{X}$ is $\mathrm{R} 2(\mathrm{G} 2, \mathrm{~B} 2)$ and $\mathrm{Y}$ is $\mathrm{R} 2(\mathrm{G} 2, \mathrm{~B} 2)$ then $\mathrm{W}$ is $\mathrm{C} 2$ & IF $\mathrm{X}$ is $\mathrm{R} 4(\mathrm{G} 4, \mathrm{~B} 4)$ and $\mathrm{Y}$ is $\mathrm{R} 2(\mathrm{G} 2, \mathrm{~B} 2)$ then $\mathrm{W}$ is $\mathrm{C} 3$ \\
\hline IF $\mathrm{X}$ is $\mathrm{R} 2(\mathrm{G} 2, \mathrm{~B} 2)$ and $\mathrm{Y}$ is $\mathrm{R} 3(\mathrm{G} 3, \mathrm{~B} 3)$ th & 4) and $\mathrm{Y}$ is $\mathrm{R} 3(\mathrm{G} 3, \mathrm{~B} 3)$ then $\mathrm{W}$ is $\mathrm{C} 4$ \\
\hline IF $\mathrm{X}$ is $\mathrm{R} 2(\mathrm{G} 2, \mathrm{~B} 2)$ and $\mathrm{Y}$ is $\mathrm{R} 4(\mathrm{G} 4, \mathrm{~B} 4)$ then $\mathrm{W}$ is $\mathrm{C} 3$ & IF $\mathrm{X}$ is $\mathrm{R} 4(\mathrm{G} 4, \mathrm{~B} 4)$ and $\mathrm{Y}$ is $\mathrm{R} 4(\mathrm{G} 4, \mathrm{~B} 4)$ then $\mathrm{W}$ is $\mathrm{C} 4$ \\
\hline
\end{tabular}

Fuzzy reasoning rule (1)

With above fuzzy reasoning rules, we have the qualitative range variable $\mathrm{C} 1$ to $\mathrm{C} 4$. Then, the second fuzzy membership function defined as Figure 4 is used to obtain the final membership degree. For example, each $\mathrm{G}$ channel value is given to the membership function defined in Figure 3 to compute the membership degree. Then the reasoning rule (1) is applied with Max-Min method. Then the second membership function defined as Figure 4 is applied to determine the membership degree and it is defuzzified by center of gravity method as formula (2).

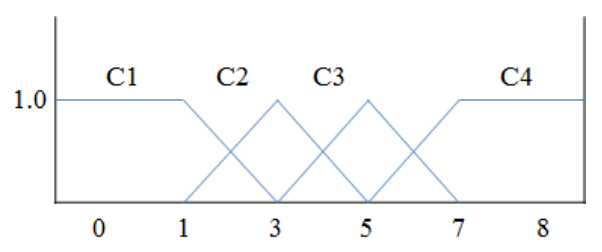

Figure 4. Membership function - second part

$$
W=\frac{\sum u(X) X}{\sum u(X)}
$$

Then the decision rule for candidate area of crack is defined as Table 2.

Table 2. Criteria for crack candidates

\begin{tabular}{|c|c|}
\hline $0<W<2$ & \\
\hline $2<W<4$ & Candidate Cracks \\
\hline $4<W<6$ & \\
\hline $6<W<8$ & Noise Area \\
\hline
\end{tabular}

\subsection{Further Refinement by Self Organizing Map Algorithm}

RGB color information may not be sufficiently strong to distinguish cracks from noises. Thus we apply self-organizing map algorithm on the image after applying fuzzy method shown as Figure 5. 


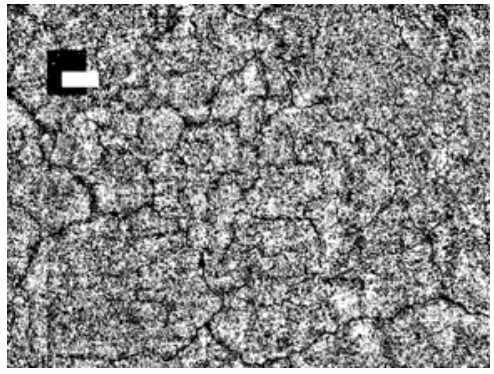

Figure 5. Image after applying fuzzy method

SOM is an unsupervised neural network learning algorithm that mimics the characteristics of human cerebral cortex and has been successfully applied to many engineering applications [23]. The performance of SOM learning is known as being influenced by the type of learning radius shown as Figure 6 and we adopt the rectangle type in this paper.

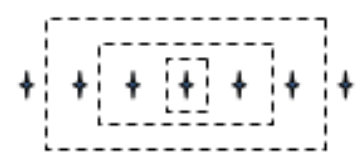

(a) One dimensional learning radius

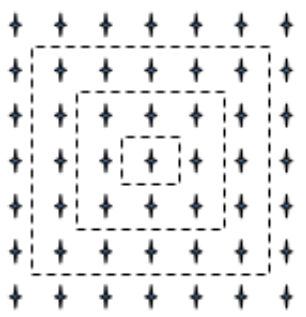

(b) Rectangle type learning radius

Figure 6. Learning types of SOM

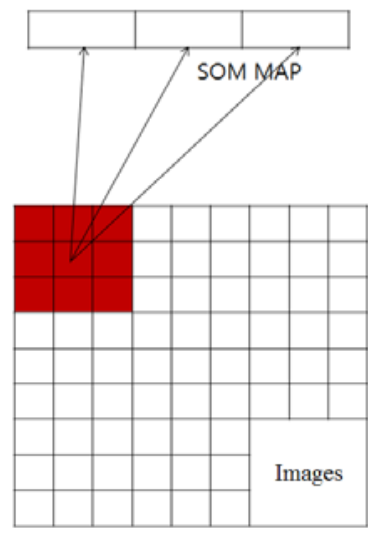

Figure 7. Applying SOM algorithm

From the locally smoothed image, we apply average gray value of $3 \times 3$ mask shown as Figure 7 to SOM learning and the output is computed by formula (3) with connection strengths controlled by formula (4).

$$
\begin{aligned}
& D(j)=\sum_{i}\left(W_{j i}-X_{i}\right)^{2} \\
& W_{j i}^{k+1}=W_{j i}^{k}+a\left(x_{i}-W_{j i}^{k}\right)
\end{aligned}
$$

where $D$ denotes the similarity, $X$ denotes the pattern, $W$ is the connection strength and $\alpha$ is the learning rate. 
The same patterns of $3 \times 3$ mask and average gray values are used to recognize any minute candidate cracks from the image after fuzzy method shown as Figure 8 . The baselines in Figure 8 are removed afterwards.

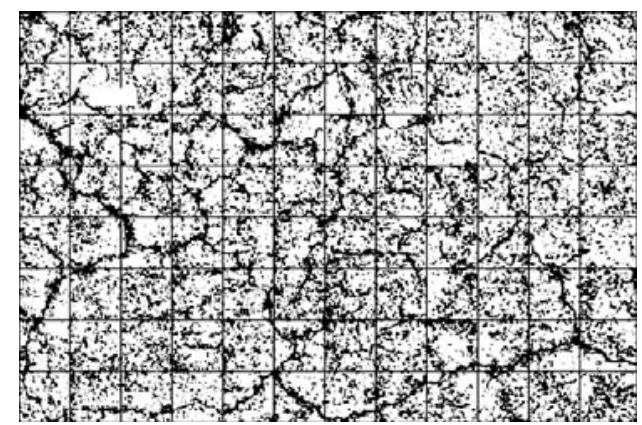

Figure 8. After applying SOM

\subsection{Noise Removal by Density Information}

Cracks have lower density and lower brightness, higher length/width rate than that of random noise as shown in Figure 9. Thus, we use formula (5) after applying Grassfire algorithm [21].

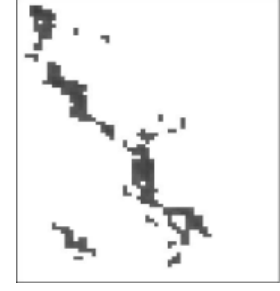

(a) Crack

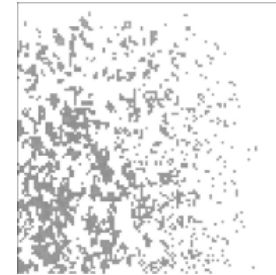

(b) Noise

Figure 9. Density differences

$$
f=\frac{A_{o b}}{A_{x} \times A_{u}}
$$

where $A x, A_{u}$ denotes the width and height of rectangle circumscribed with objects extracted by Grassfire algorithm in respectively and $A_{o b}$ denotes the number of pixels in extracted object.

Then we apply the final decision rule shown as Table 3 and the result is like as shown in Figure 10. The experimental threshold 0.3 was obtained from prior observation of 10 random images not used in this experiment that the characteristic coefficient $f$ of formula (5) has certain tendency. Since cracks have higher length/width rate, that tendency with respect to the object labelling Grassfire algorithm can easily be formulated.

Table 3. Final crack decision rule

\begin{tabular}{cl}
\hline $\mathrm{f}>=0.3$ & Noise \\
\hline $\mathrm{f}<0.3$ & Crack \\
\hline
\end{tabular}




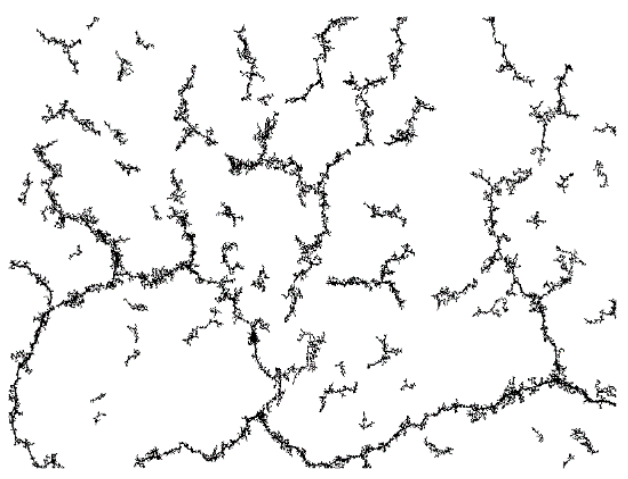

Figure 10. Final crack extraction

For the analysis, we compute the length, width, and the angle of the identified crack with respect to the method used in [24].

\section{EXPERIMNET AND ANALYSIS}

The proposed method was implemented with Microsoft Visual studio 2008 and experiments were performed on IBM-compatible PC with Intel i5 3.0 GHz CPU and 4GB RAM. Thirty Digital images of concrete surface taken with a Canon 350D digital camera of $800 \times 600$ size were used in the experiments.

In our previous attempt [21], the gray value was used in crack extraction as is. Thus, the method was sensitive to the influence of the outdoor light or may face with environment like low brightness contrast between concrete surface and crack candidates. However, the proposed method uses R, G, B values as color information and applies fuzzy method and SOM in noise removal.
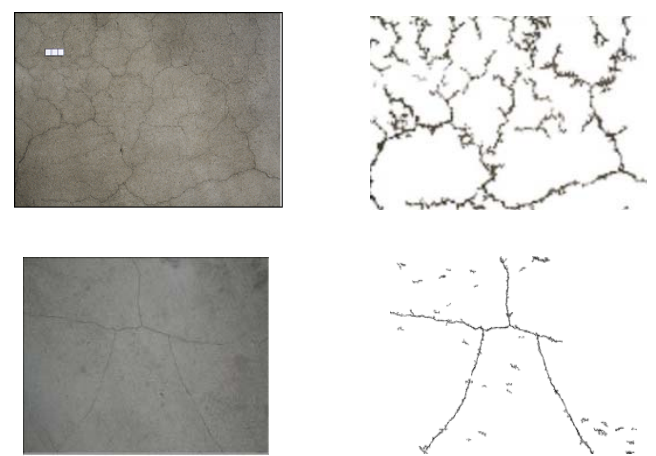

(a) Original Image

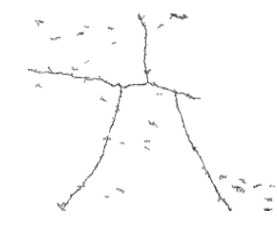

(b) Previous 1 [21]
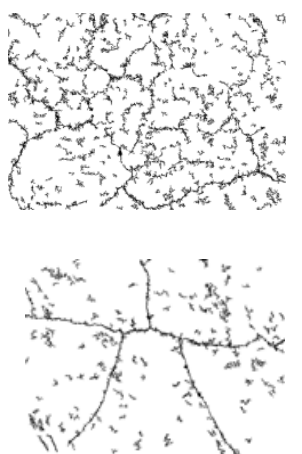

(c) Previous $2[24]$
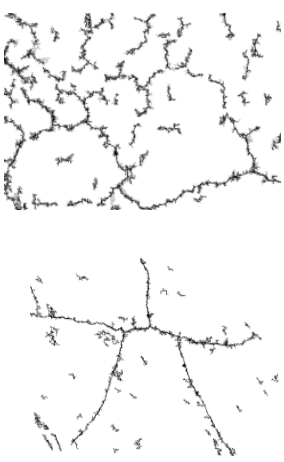

(d) Proposed method

Figure 11. Comparison of the proposed method and previous methods

There is another related approach with slightly sdfferent purposes. In [25], it tries to recognize five crack patterns - horizontal, vertical, left diagonal, right diagonal, and undirectional - with back propagation neural network in conjunction with inage processing techniques. During the process, it is supposed to extract the cracks but as shown in Figure 11 (d), that method is especially weak for "undirectional" cracks in that the system is prone to recognize false positive noises as cracks dur to low intensity contrast.

We believe that such improvement gives us more accurate crack identification result shown as Figure 12 as a comparative example in that the proposed method is more accurate and discriminative in extracting minute cracks. However, if the concrete surface has relatively long $(>1 \mathrm{~cm})$ furrows or filths, the proposed method fails to extract cracks correctly as shown in Figure 12. 

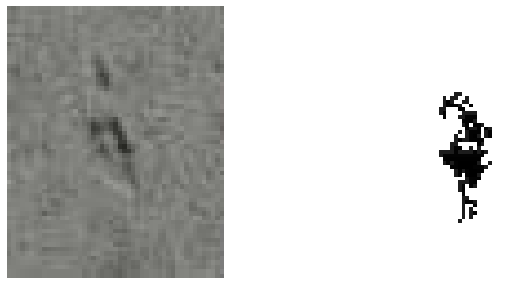

Figure 12. False identification example

Figure 13 demonstrates the labelled crack result in order to analyze some characteristics of cracks. Such characteristics - width, length, direction - are summarized in Table 4.

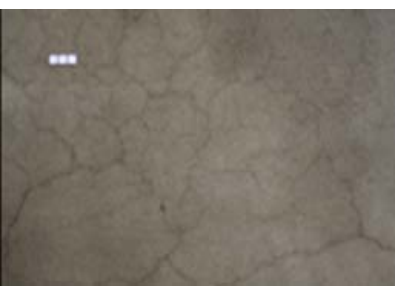

(a) Original image

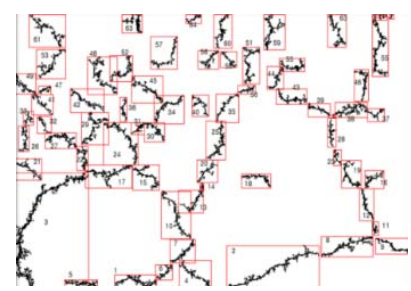

(b) Crack identified

Figure 13. Crack identification example

Table 4. Crack characteristics for Figure 17

\begin{tabular}{cccccccc}
\hline Crack\# & Length(cm) & Width(cm) & ${\text { Angle }\left({ }^{\circ}\right)}$ Crack\# & Length(cm) & Width(cm) & Angle $\left({ }^{\circ}\right)$ \\
\hline 1 & 11.127 & 0.276 & 24.23 & 14 & 4.533 & 0.409 & 48.01 \\
2 & 14.654 & 0.743 & 56.25 & 15 & 1.919 & 0.231 & 40.49 \\
3 & 3.723 & 0.323 & 12.97 & 16 & 3.954 & 0.212 & 49.57 \\
4 & 6.211 & 0.319 & 20.21 & 17 & 2.910 & 0.301 & 50.74 \\
5 & 4.214 & 0.218 & 22.88 & 18 & 4.507 & 0.499 & 39.23 \\
6 & 6.035 & 0.349 & 56.08 & 19 & 1.618 & 0.248 & 31.94 \\
7 & 3.727 & 0.228 & 64.54 & 20 & 2.163 & 0.229 & 23.82 \\
8 & 3.651 & 0.361 & 53.13 & 21 & 4.319 & 0.369 & 63.54 \\
9 & 3.286 & 0.249 & 46.54 & 22 & 3.158 & 0.368 & 25.55 \\
10 & 3.722 & 0.408 & 37.20 & 23 & 3.009 & 0.320 & 40.42 \\
11 & 5.952 & 0.410 & 49.25 & 24 & 4.449 & 0.425 & 57.26 \\
12 & 4.654 & 0.336 & 61.86 & 25 & 2.998 & 0.521 & 40.90 \\
13 & 3.873 & 0.409 & 25.03 & 26 & 1.989 & 0.229 & 28.41 \\
\hline
\end{tabular}

For all 30 images used in this experiment, we identified $97.3 \%$ of cracks as summarized in Table 5 where the ground truth cracks are verified by field engineer.

Table 5. Crack identification statistics

\begin{tabular}{cccc}
\hline Images & \# of Cracks & Identified & Accuracy \\
30 & 1319 & 1283 & $97.3 \%$ \\
\hline
\end{tabular}

From literature review, this result is better than using other various image processing techniques [15] which reported the error identification rate of 3.56-8.95\% from different image set using 5 different image processing techniques.

\section{CONCLUSION}

In this paper, we propose a new method to extract and analyze cracks on concrete slab structure by intelligent image processing techniques. While previous methods use gray value of the image directly, we use 
$\mathrm{R}, \mathrm{G}, \mathrm{B}$ channel values as color information and apply fuzzy reasoning and SOM algorithm in extracting candidate cracks and removing noises. With those careful treatments, we can successfully extract minute cracks which were often ignored in previous studies. Then some characteristics of cracks such as length, width, and direction could be easily analyzed.

While the aim of this research was confined to extract cracks accurately and computes some basic characteristics of cracks, we expect that more intelligent and useful tools that can analyze the progression of cracks and directions of cracking for more intelligent maintenance of concrete structure in future research.

\section{REFERENCES}

[1] R. Rajni, et al., "Complementary Split Ring Resonator based Sensor for Crack Detection," International Journal of Electrical and Computer Engineering, vol/issue: 5(5), pp. 1012-1017, 2015.

[2] J. P. Sawyer, et al., "Structural damage detection and identification using fuzzy logic," AIAA journal, vol/issue: 38(12), pp. 2328-2335, 2000.

[3] N. Bakhary, et al., "Structure damage detection using neural network with multi-stage substructuring," Advances in Structural Engineering, vol/issue: 13(1), pp. 95-110, 2010.

[4] P. Beena, et al., "Structural damage detection using fuzzy cognitive maps and Hebbian learning," Applied Soft Computing, vol/issue: 11(1), pp. 1014-1020, 2011

[5] D. G. Aggelis, et al., "NDT approach for characterization of subsurface cracks in concrete," Construction and Building Materials, vol/issue: 25(7), pp. 3089-3097, 2011.

[6] D. A. Tibaduiza, et al., "Damage classification in structural health monitoring using principal component analysis and self-organizing maps," Structural Control and Health Monitoring, vol/issue: 20(10), pp. 1303-1316, 2013.

[7] R. P. Dayal, et al., "Analysis of smart crack detection methodologies in various structures," Journal of Engineering and Technology Research, vol/issue: 3(5), pp. 139-147, 2011.

[8] B. Gunes, et al., "Structural Health Monitoring and Damage Assessment Part II: Application of the Damage Locating Vector (DLV) Method to the ASCE Benchmark Structure Experimental Data," International Journal of Physical Sciences, vol/issue: 7(9), pp. 1509-1515, 2012.

[9] Z. Chen, et al., "Image-based framework for concrete surface crack monitoring and quantification," Advances in Civil Engineering, pp. 1-18, 2010.

[10] M. Dilena, et al., "Dynamic testing of a damaged bridge," Mechanical Systems and Signal Processing, vol/issue: 25(1), pp. 1485-1507, 2011.

[11] K. B. Kim, et al., "Recognition of concrete surface cracks using the ART1-based RBF network," Advances in Neural Networks-ISNN 2006, Springer Berlin Heidelberg, pp. 669-675, 2006.

[12] I. Abdel-Qader, et al., "Analysis of edge-detection techniques for crack identification in bridges," Journal of Computing in Civil Engineering, vol/issue: 17(4), pp. 255-263, 2003.

[13] T. Nishikawa, et al., "Concrete crack detection by multiple sequential image filtering," Computer Aided Civil and Infrastructure Engineering, vol/issue: 27(1), pp. 29-47, 2012.

[14] Y. Fujita, et al., "A robust automatic crack detection method from noisy concrete surfaces," Machine Vision and Applications, vol/issue: 22(2), pp. 245-254, 2011.

[15] T. Yamaguchi, et al., "Fast crack detection method for large-size concrete surface images using percolation-based image processing," Machine Vision and Applications, vol/issue: 21(5), pp. 797-809, 2010.

[16] G. Li, et al., "Image-based Method for Concrete Bridge Crack Detection," Journal of Information \& Computational Science, vol/issue: 10(8), pp. 2229-2236, 2013.

[17] A. Farhidzadeh, et al., "A vision-based technique for damage assessment of reinforced concrete structures," In SPIE Smart Structures and Materials + Nondestructive Evaluation and Health Monitoring, International Society for Optics and Photonics, pp. 90642H-90642H, 2014.

[18] P. Prasanna, et al., "Computer-vision based crack detection and analysis," In SPIE Smart Structures and Materials+ Nondestructive Evaluation and Health Monitoring (pp. 834542-834542). International Society for Optics and Photonics, 2012.

[19] B. Y. Lee, et al., "Surface Crack Evaluation Method in Concrete Structures," Journal of the Korean Society for Nondestructive Testing, pp. 173-182, 2007.

[20] Y. W. Woo, et al., "FCM-based RBF network in identifying concrete slab surface cracks," Intelligent Systems Design and Applications, ISDA'08. Eighth International Conference on. IEEE, vol. 1, pp. 664-669, 2008.

[21] K. B. Kim, et al., "Analysis of Concrete Slab Surface Cracks Using ART2-based Hybrid Neural Network," Information-An International Interdisciplinary Journal, vol/issue: 16(1B), pp. 777-782, 2013.

[22] V. Godbole, "Performance analysis of clustering protocol using fuzzy logic for wireless sensor network," IAES International Journal of Artificial Intelligence (IJ-AI), vol/issue: 11(3), pp. 103-111, 2012.

[23] T. Kohonen, et al., "Engineering applications of the self-organizing map," Proceedings of the IEEE, vol/issue: 84(10), pp. 1358-1384, 1996.

[24] K. B. Kim, et al., "Vision based Crack Identification and Analysis on the Surface of Concrete Slab Structures," Information-An International Interdisciplinary Journal, vol/issue: 18(6A), pp. 2381-2386, 2015.

[25] B. Y. Lee, et al., "A Technique for Pattern Recognition of Concrete Surface Cracks," Journal of the Korea Concrete Institute, vol/issue:17(3), pp. 369-374, 2006 


\section{BIOGRAPHIES OF AUTHORS}
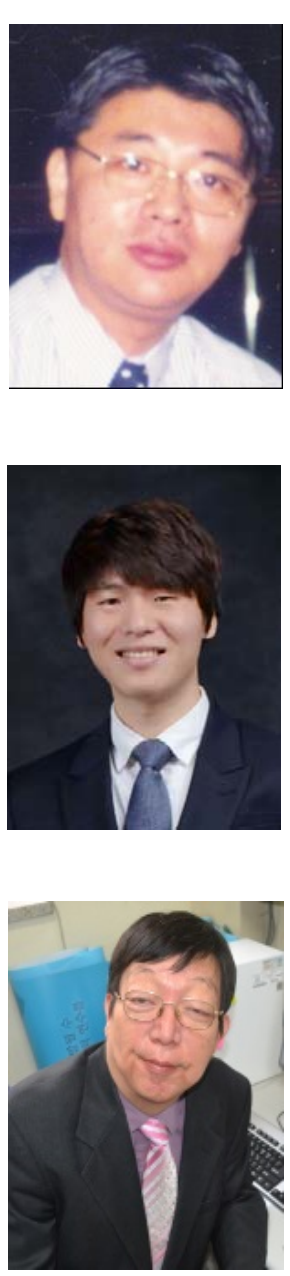

Kwang Baek Kim. Kwang Baek Kim received his M.S. and Ph.D. degrees from the Department of Computer Science, Pusan National University, Busan, Korea, in 1993 and 1999, respectively. From 1997 to the present, he is a professor at the Department of Computer Engineering, Silla University, Korea. He is currently an associate editor for Journal of Intelligence and Information Systems and The Open Computer Science Journal (USA). His research interests include fuzzy neural network and applications, bioinformatics, and image processing.

Hyun Jun Park. He received his M.S. degrees from the Department of Computer Science, Pusan National University, Busan, Korea, in 2009. From 2009 to the present, he is a Ph.D. course student at the Department of Computer Engineering, Pusan National University, Korea. His research interests include computer vision, image processing, neural network and applications.

Doo Heon Song. Doo Heon Song received a B.S. degree in Statistics \& Computer Science from Seoul National University and M.S. degree Computer Science from the Korea Advanced Institute of Science and Technology in 1983. He received his Ph.D. Certificate in Computer Science from the University of California in 1994. Form 1983-1986, he was a research scientist at the Korea Institute of Science and Technology. He has been a professor at the Department of Computer Games, Yong-in Songdam College, Korea, since 1997. His research interests include ITS, machine learning, artificial intelligence, medical image processing, cognitive, and game intelligence. 